\title{
Combining Peripheral Nerve Grafts and Chondroitinase Promotes Functional Axonal Regeneration in the Chronically Injured Spinal Cord
}

\author{
Veronica J. Tom, ${ }^{\star}$ Harra R. Sandrow-Feinberg, ${ }^{\star}$ Kassi Miller, Lauren Santi, Theresa Connors, Michel A. Lemay, \\ and John D. Houlé \\ Department of Neurobiology and Anatomy, Drexel University College of Medicine, Philadelphia, Pennsylvania 19129
}

\begin{abstract}
Because there currently is no treatment for spinal cord injury, most patients are living with long-standing injuries. Therefore, strategies aimed at promoting restoration of function to the chronically injured spinal cord have high therapeutic value. For successful regeneration, long-injured axons must overcome their poor intrinsic growth potential as well as the inhibitory environment of the glial scar established around the lesion site. Acutely injured axons that regenerate into growth-permissive peripheral nerve grafts (PNGs) reenter host tissue to mediate functional recovery if the distal graft-host interface is treated with chondroitinase $A B C(C h A B C)$ to cleave inhibitory chondroitin sulfate proteoglycans in the scar matrix. To determine whether a similar strategy is effective for a chronic injury, we combined grafting of a peripheral nerve into a highly relevant, chronic, cervical contusion site with ChABC treatment of the glial scar and glial cell line-derived neurotrophic factor (GDNF) stimulation of long-injured axons. We tested this combination in two grafting paradigms: (1) a peripheral nerve that was grafted to span a chronic injury site or (2) a PNG that bridged a chronic contusion site with a second, more distal injury site. Unlike GDNF-PBS treatment, GDNF-ChABC treatment facilitated axons to exit the PNG into host tissue and promoted some functional recovery. Electrical stimulation of axons in the peripheral nerve bridge induced c-Fos expression in host neurons, indicative of synaptic contact by regenerating fibers. Thus, our data demonstrate, for the first time, that administering ChABC to a distal graft interface allows for functional axonal regeneration by chronically injured neurons.
\end{abstract}

\section{Introduction}

A widely accepted, acute treatment paradigm may eventually be developed, but it is not always feasible or advisable to surgically intervene shortly after sustaining a spinal cord injury (SCI). Therefore, strategies aimed at promoting restoration of function in chronically injured spinal cord have great therapeutic value, especially because most injured patients are living to full life expectancy.

One barrier to successful regeneration in the adult CNS is the diminished axonal growth capacity after maturation (Kalil and Skene, 1986; Fawcett, 2006; Ruff et al., 2008). Moreover, although acutely injured adult axons do not regrow as quickly as younger ones, chronically injured axons are even more impaired in their propensity to regenerate (Tetzlaff et al., 1991; Dolbeare and Houle, 2003). Chronically injured axons need additional stimulation, e.g., exogenous neurotrophins, to spur a regenerative response. Previous work from the laboratory demonstrated that treating a chronic cervical hemisection site with neurotrophic factors, including glial cell line-derived neurotrophic factor

\footnotetext{
Received July 28, 2009; revised 0ct. 2, 2009; accepted 0ct. 14, 2009.

This work was supported by National Institutes of Health/National Institute of Neurological Disorders and Stroke Grant NS26380 and the Christopher and Dana Reeve Foundation.

*V.J.T. and H.R.S.-F. contributed equally to this study.

Correspondence should be addressed to Dr. John D. Houlé, Department of Neurobiology and Anatomy, Drexel

University College of Medicine, 2900 Queen Lane, Philadelphia, PA 19129. E-mail: jhoule@drexelmed.edu. D0I:10.1523/JNEUROSCI.3641-09.2009

Copyright $\odot 2009$ Society for Neuroscience $\quad$ 0270-6474/09/2914881-10\$15.00/0
}

(GDNF), before grafting a peripheral nerve (PNG) into the lesion cavity was associated with an upregulation of growth-associated proteins (Storer et al., 2003) and promoted significantly more axons to regenerate into the graft (Ye and Houle, 1997; Dolbeare and Houle, 2003). Recently, we showed that GDNF treatment of a subchronic, unilateral contusion site also resulted in regeneration of injured axons into a peripheral nerve $(\mathrm{PN})$ that was grafted 4 weeks after injury (Sandrow et al., 2008). Because cervical contusions are the most common form of SCI in human patients (University of Alabama at Birmingham, 2008), these findings indicate that it is feasible to use neurotrophins and transplants to promote long-injured axons to regrow in a clinically relevant model.

Another barrier to successful regeneration is the glial scar that is formed immediately around the lesion (Silver and Miller, 2004; Fawcett, 2006; Yiu and He, 2006). Reactive astrocytes, fibroblasts, and $\mathrm{NG} 2{ }^{+}$progenitor cells within the scar quickly upregulate their production of inhibitory molecules, including multiple members of the chondroitin sulfate proteoglycan (CSPG) family (McKeon et al., 1999; Jones et al., 2003; Galtrey and Fawcett, 2007), which appear to play a key role in regenerative failure. Digestion of CSPGs by the bacterial enzyme chondroitinase $\mathrm{ABC}$ (ChABC), which cleaves the inhibitory sugar moiety from the protein core of CSPG, results in improved regrowth of acutely injured axons in vivo and has been associated with some functional recovery (Bradbury et al., 2002; Caggiano et al., 2005; Houle et al., 2006; Tester and Howland, 2008). Specifically, we 
showed that, if a distal PNG-host SCI interface is treated with ChABC, significantly more axons crossed the usually inhospitable border to reenter the spinal cord (Houle et al., 2006). Whether ChABC would improve regeneration in a chronic situation has not been studied until now.

We used two grafting paradigms: (1) a PN to span a chronic injury site or (2) a PNG that bridged a chronic contusion site with a second, more distal injury. Our anatomical, behavioral, and physiological assessments provide the first evidence that ChABC treatment results in modest recovery attributable to regeneration by chronically injured neurons.

\section{Materials and Methods}

\section{Surgical procedures}

All procedures complied with Institutional Animal Care and Use Committee and National Institutes of Health guidelines for experimentation with laboratory animals. After all survival surgeries, animals were given ampicillin $(200 \mathrm{mg} / \mathrm{kg})$ and buprenorphine $(0.1 \mathrm{mg} / \mathrm{kg})$ postoperatively and placed on a thermal barrier to recover. They were returned to their cages once they became alert and responsive. All rats receiving PNGs were given cyclosporine A (CsA) $(10 \mathrm{mg} / \mathrm{kg}$, s.c., Sandimmune; Novartis Pharmaceuticals) daily starting $3 \mathrm{~d}$ before receiving their grafts. After 2 weeks, these animals received CsA via their drinking water $(100 \mathrm{mg} / \mathrm{kg})$. This immunosuppression protocol has been used previously to successfully prevent against host rejection and promote long-term survival of an intraspinal graft (Tobias et al., 2003; Houle et al., 2006).

Cervical hemicontusion injuries. Adult female Sprague Dawley rats were injured as described previously (Sandrow et al., 2008). Briefly, animals were injected intraperitoneally with ketamine $(60 \mathrm{mg} / \mathrm{kg})$ and xylazine $(10 \mathrm{mg} / \mathrm{kg})$. The right, dorsal surface of C5 was exposed by laminectomy. The vertebral column was stabilized by clamping the $\mathrm{C} 3$ and C7 vertebral bodies with forceps fixed to the base of an Infinite Horizon Impact Device (Precision Systems and Instrumentation). The animals were situated on the platform, and the $1.6 \mathrm{~mm}$ stainless steel impactor tip was positioned over the midpoint (medial to lateral) of the right side of C5. The animals were impacted with a $200 \mathrm{kdyne}$ force with displacement of tissue to a depth of 1600-1800 $\mu \mathrm{m}$. The overlying musculature was closed using 4-0 sutures, and the skin was closed using wound clips.

To determine the efficacy of treating a chronic contusion site with ChABC, six animals were unilaterally contused at C5 as described above. Four weeks later, the contused rats were anesthetized with isoflurane, and the C5 injury site was exposed. Necrotic tissue in the cavity was removed by gentle aspiration as described by Sandrow et al. (2008). Gelfoam saturated with ChABC $(n=3 ; 50 \mathrm{U} / \mathrm{ml}$; Seikagaku) or PBS $(n=3)$ was inserted into the cavity and then refreshed every $15 \mathrm{~min}$ over a $1 \mathrm{~h}$ period. Additionally, $1 \mu \mathrm{l}$ of $\mathrm{ChABC}(50 \mathrm{U} / \mathrm{ml})$ was microinjected into tissue 1 $\mathrm{mm}$ rostral and caudal to the injury site. The dura and overlying musculature were sutured, and the skin was closed with wound clips. Animals were perfused with $4 \%$ paraformaldehyde (PFA) $3 \mathrm{~d}$ later, and tissue sections were processed by immunohistochemical staining (see below, Histology).

Grafting peripheral nerve to span the cavity. One week before grafting, donor rats were anesthetized with isoflurane. The tibial nerve was isolated, ligated, and then completely severed using microscissors. Overly- b

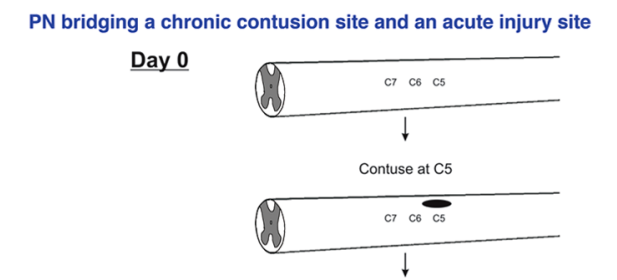

Day 56 (8wks)

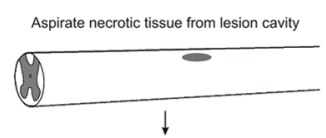

$\downarrow$

Treat lesion cavity with GDNF or GDNF+ChABC
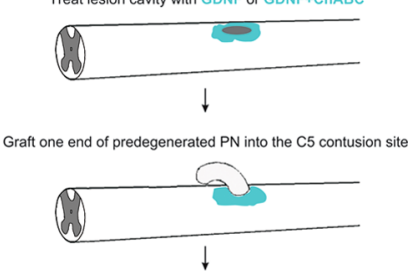
Day 77 (11 wks) Aspirate dorsal quadrant at $C 7$ and treat with $P B S$ or $C h A B C$

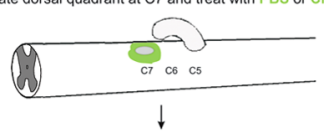

Day 81 (11 wks 3d)

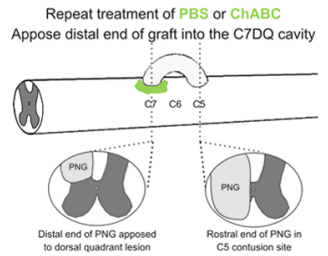
Figure 1. Schematics of the two grafting paradigms. $\boldsymbol{a}$ diagrams the design and timeline for the experiments in which a
peripheral nerve graft spanned a chronic $\mathrm{C} 5$ contusion site. $\boldsymbol{b}$ diagrams the design and timeline for the experiments in which a peripheral nerve was used to bridge a chronic, $\mathrm{C} 5$ contusion site, and a more distal, acute injury site at $\mathrm{C}$.

ing musculature was sutured shut, and the skin was closed using would clips. One week later, donor rats were anesthetized with ketamine (60 $\mathrm{mg} / \mathrm{kg}$ ) and xylazine $(10 \mathrm{mg} / \mathrm{kg})$, and the predegenerated tibial nerve was removed and kept in ice-cold HBSS until grafted. Three to four short segments were obtained from one tibial nerve.

A schematic of this grafting paradigm can be seen in Figure 1a. Eight weeks after the unilateral cervical injury, the contused rats were anesthetized using isoflurane. The $\mathrm{C} 5$ contusion site was exposed, and a small slit was made in the overlying dura using a microknife. The necrotic tissue within the lesion cavity was gently removed by aspiration. Great care was taken to not disturb the glial scar or underlying spinal cord that was spared from the initial injury. Although acutely injured axons readily regenerate into a predegenerated PNG, chronically injured axons need additional stimulation (Ye and Houle, 1997). Therefore, Gelfoam saturated with $20 \mu \mathrm{g} / \mathrm{ml} \mathrm{GDNF}$ (R \& D Systems) in PBS ( $n=10)$ or $20 \mu \mathrm{g} / \mathrm{ml}$ GDNF and ChABC ( $50 \mathrm{U} / \mathrm{ml} ; n=10)$ in PBS was placed into the lesion cavity of all animals for $60 \mathrm{~min}$ (Dolbeare and Houle, 2003; Storer et al., 2003). The Gelfoam was replaced three times with fresh, saturated Gelfoam. Additionally, $1 \mu \mathrm{l}$ of $20 \mu \mathrm{g} / \mathrm{ml}$ GDNF in PBS or $1 \mu \mathrm{lof} 20 \mu \mathrm{g} / \mathrm{ml}$ GDNF and $50 \mathrm{U} / \mathrm{ml}$ ChABC in PBS was microinjected into ipsilateral spinal cord $1 \mathrm{~mm}$ rostral and $1 \mathrm{~mm}$ caudal to the contusion site using a pulled pipette. A segment of predegenerated tibial nerve long enough to span the lesion site $(\sim 2-3 \mathrm{~mm})$ was inserted into the cavity. The dura was stitched shut using 10-0 sutures. A small piece of SILASTIC membrane (BioBrane; UDL Laboratories) was placed over the exposed dura. Overlying musculature was sutured closed, and the skin was closed using wound clips.

Grafting a peripheral nerve to bridge a contusion injury and a dorsal quadrant injury. One week before grafting, tibial nerves of donor rats were ligated and cut as described above. One week later, donor rats were anesthetized with ketamine and xylazine. The predegenerated tibial 
nerve was removed immediately before grafting. Unlike with the grafts that spanned the cavity, the grafts that bridged a C5 unilateral contusion site and a C7 dorsal quadrant (DQ) injury were segments of tibial nerve $\sim 15 \mathrm{~mm}$ in length (Fig. $1 b$ ).

Eight weeks after the $\mathrm{C} 5$ hemicontusion injury, the contused rats were anesthetized with isoflurane. The dura above the contusion site was cut with a microknife, and necrotic tissue within the lesion cavity was gently aspirated. The lesion site and tissue immediately rostral and caudal were treated with GDNF and ChABC $(n=14)$ or GDNF alone $(n=11)$ as described above. One end of a predegenerated tibial nerve was isolated from a donor rat, and $\sim 2-3 \mathrm{~mm}$ of the perineurium was peeled from the proximal nerve end. This end was placed into the C5 contusion site so that it apposed the rostral cavity area and was secured by suturing perineurium to the dura. The distal end of the PNG was left free outside of the spinal column, along the C6-C8 vertebrae. The dura and overlying musculature were closed using sutures, and the skin was closed using wound clips. Three weeks later, the animals were anesthetized. A laminectomy was performed on the right side of the C7 vertebral process, and part of the DQ was aspirated out, creating a cavity of $\sim 1 \mathrm{~mm}^{3}$. This time point was chosen so that chronically injured axons had ample time to grow into and through the graft to its end. Thus, the axons would be adjacent to the host spinal cord after graft apposition to $\mathrm{C} 7$ and best maximize the potential of these axons to exit the graft soon after apposition to the treated distal interface. Animals that received GDNF and ChABC in the chronic C5 cavity received microinjections of $0.5 \mu \mathrm{l}$ of $\mathrm{ChABC}(20 \mathrm{U} / \mathrm{ml})$ immediately rostral, caudal, and ventral to the fresh DQ lesion. Animals that received GDNF alone in the chronic C5 cavity received microinjections of $0.5 \mu \mathrm{l}$ of PBS immediately rostral, caudal, and ventral to the DQ lesion. This pattern of microinjections was repeated $3 \mathrm{~d}$ later. After the second series of injections, the free, distal end of the PNG was trimmed by $1 \mathrm{~mm}$ to help spur a regenerative response and inserted into the C7DQ cavity, in which it was secured in place by suturing the perineurium to the dura. SILASTIC membrane was placed over the graft. After the musculature was sutured, the skin was closed using wound clips.

\section{Behavioral analyses}

Animals were maintained on food and water ad libitum with a $12 \mathrm{~h}$ light/dark cycle. After acclimation to the testing apparatus over a 1 week period, baseline scores for forelimb open-field locomotion and Tread Scan (Clever Sys) were obtained for each animal. Animals then were subjected to the unilateral C5 contusion injury. Open-field forelimb evaluation began $2 \mathrm{~d}$ postoperatively and was repeated every other week until grafting. After grafting, animals were evaluated weekly for 8 weeks.

Open-field locomotion. Forelimb function was evaluated in an open field measuring $2.5 \times 3$ feet, and the rats were observed for 4 min by at least two individuals blinded to the treatment condition. The forelimb locomotor scale (FLS), devised at Drexel University College of Medicine from observation of recovery patterns in cervically injured rats, is a 17-point scale that defines deficits based on range of motion, level of weight support, and whether the paw is placed parallel to the body (Cao et al., 2008; Sandrow et al., 2008). The FLS is thus similar in assessment style to the Basso-Beattie-Bresnahan (BBB) rating scale for hindlimb function (Basso et al., 1995). Each animal was scored during direct observation in the open field for $4 \mathrm{~min}$ and videotaped for later reference if necessary.

Forced locomotion (Tread Scan). Forelimb and hindlimb locomotor capabilities were assessed during a $20 \mathrm{~s}$ period of forced locomotion. The Tread Scan system, consisting of a clear treadmill with a camera to allow for recording of step cycles from beneath the rat (Clever Sys), was used to obtain and evaluate three aspects of gait (track width, paw print area, and stride time). A background image was taken before each test day. The treadmill speed was adjusted so that every animal had a consistent gait pattern. The recorded AVI file was converted to an MPEG file and analyzed with the Clever Sys Tread Scan software.

Statistical analysis. Behavioral data were analyzed by two-way ANOVA between groups and time, with time taken as a repeated measure. The
FLS and BBB scores covered a sufficient range over time to approximate a normal distribution and therefore could be analyzed in this manner. However, post hoc analysis for the FLS and BBB data did not meet conditions of normality and therefore were analyzed with the Mann-Whitney $U$ test to examine the differences between GDNFChABC-treated and GDNF-PBS-treated animals in each grafting paradigm. Post hoc analysis for the grid test was performed using the Bonferroni's test. All statistics were conducted using SPSS (version 16.0). A $p$ value $<0.05$ was considered significant.

Electrical stimulation of the PNG bridge. Animals with PNGs bridging a C5 contusion injury and C7DQ site that had been treated with vehicle $(n=3)$ or ChABC $(n=3)$ were anesthetized with ketamine and xylazine. The graft was exposed, and the middle of the PNG was lifted from surrounding tissue and placed onto a bipolar hook electrode (catalog \#PBCA6775; FHC). The graft was bathed in body temperature mineral oil while it was stimulated for $1 \mathrm{~h}(1 \mathrm{~mA}$ amplitude, $100 \mu$ s pulse duration, and $50 \mathrm{~Hz}$ frequency). Animals were killed and perfused $2 \mathrm{~h}$ later with $4 \%$ PFA.

Labeling of regenerated axons in PNG. To label axons that had regenerated into the PNG that spanned the lesion cavity, animals were anesthetized, C5 was exposed, and $1 \mu \mathrm{l}$ of $10 \%$ biotinylated dextran amine (BDA) (3000 molecular weight; Invitrogen) was microinjected into the center of the graft. Three days later, animals were perfused with $4 \%$ PFA.

To label axons that regenerated into the PNG that bridged the C5 unilateral contusion and the C7DQ, animals were anesthetized, and the cord and graft were exposed. The graft was cut, and the distal end was soaked with $10 \%$ BDA to label regenerating axons by tracer diffusion though the distal end of the graft. Animals were perfused with 4\% PFA $2 \mathrm{~d}$ later.

Histology. Segments of spinal cord containing the PNGs were dissected out of the perfused animals and postfixed overnight in $4 \%$ PFA at $4^{\circ} \mathrm{C}$. The tissue then was cryoprotected in $30 \%$ sucrose for at least $1 \mathrm{~d}$ before sectioning on a cryostat. For tissue containing a PNG spanning the cavity, $25 \mu \mathrm{m}$ horizontal sections were cut in a series of six. For tissue containing a PNG bridge to a C7DQ injury site, $25 \mu \mathrm{m}$ transverse sections through the apposition site were cut in a series of six. Sections were blocked in 5\% NGS, $1 \%$ BSA, $0.1 \%$ Triton X-100 in PBS for $1 \mathrm{~h}$ at room temperature before incubation in the appropriate primary antibody overnight at $4^{\circ} \mathrm{C}$. The primary antibodies used were anti-CSPG (clone CS56; Sigma), antiCSPG "stub" (2B6; Seikagaku), anti-glial acidic fibrillary protein (GFAP) (Dako), and anti-c-Fos (Sigma). Sections were rinsed in PBS and incubated in the appropriate secondary antibody overnight at $4^{\circ} \mathrm{C}$. To visualize BDA-labeled axons, sections from animals with grafts spanning the contusion cavity were incubated with streptavidin conjugated to a fluorophore (Invitrogen). Sections from animals containing PNG bridges were reacted with avidin-HRP and then diaminobenzidine (DAB) (Sigma). Sections incubated in anti-c-Fos were reacted with the appropriate secondary antibodies and then DAB. Sections were rinsed in PBS, mounted onto glass slides, and coverslipped using either VectaShield for fluorescent sections (Vector Laboratories) or dehydrated and coverslipped using Permount (Fisher Scientific) for DAB-reacted sections. Sections were imaged using a Zeiss Axioskop microscope and a Leica TCS SP2 confocal equipped with a Leica DMRE microscope.

Semithin sections. The central portion of PNGs bridging a GDNF-PBStreated $(n=5)$ or GDNF-ChABC-treated $(n=5)$ C5 contusion site and a C7DQ injury site was processed for plastic-embedded, semithin sectioning. All materials were obtained from Electron Microscopy Sciences. Briefly, grafts were rinsed in PBS, postfixed in $1 \%$ osmium tetroxide, rinsed in PBS, and stained in $2 \%$ uranyl acetate. The tissue was then dehydrated in a series of graded alcohols (70-100\%). After the tissue was dehydrated, it went through the infiltration process. The tissue underwent two changes in propylene oxide and was then incubated in a 2:1 solution of Epon/propylene oxide overnight. The tissue was changed into a mixture of Epon-812 and Araldite and then flat embedded in silicone molds. The capsules were polymerized in a $60^{\circ} \mathrm{C}$ oven for $3 \mathrm{~d}$. Afterward, $1 \mu \mathrm{m}$ sections were cut on a Reichert ultramicrotome and imaged using a Zeiss Axioskop microscope.

Quantification. To quantify the number of axons that grew into PNGs, one semithin cross-section of the PNG bridge per animal (GDNF-PBS, 
$n=5$; GDNF-ChABC, $n=5)$ was imaged, and axons were manually counted (MetaMorph; Molecular Devices). A Student's $t$ test was used to determine whether there were significant differences between the numbers of axons between the two groups (Microsoft Excel). Significance was determined if $p<0.05$.

To quantify BDA-positive $\left(\mathrm{BDA}^{+}\right)$axons that had regenerated out of PNGs spanning a chronic C5 contusion site, a virtual line 100 $\mu \mathrm{m}$ from the most caudal graft-host interface point was drawn in 10 sections $150 \mu \mathrm{m}$ apart that were reacted with a fluorescent streptavidin. The number of axons crossing this line per section was counted and totaled per animal. To determine whether there was a significant difference between the numbers of axons crossing ChABC-treated interfaces versus PBS-treated interfaces, a Student's $t$ test was performed (Microsoft Excel). A $p$ value $<0.05$ was considered significant.

To quantify $\mathrm{BDA}^{+}$regenerating axons that emerged from PNGs bridging a chronic, GDNF-PBS-treated or GDNF-ChABC-treated C5 contusion site and a PBS-treated or ChABCtreated C7DQ injury site, transverse C7 sections (five sections per animal) containing a PNG were imaged. A virtual line was drawn $500 \mu \mathrm{m}$ from the most ventral point of the graft-host interface, and axons crossing that line were counted. The GDNF-PBS and GDNFChABC groups were compared statistically using a Student's $t$ test (Microsoft Excel). Significance was determined if $p<0.05$.

To quantify the number of c-Fos ${ }^{+}$cells after stimulation of the PNG bridge, four transverse sections containing a PNG per electrophysiologically stimulated, ChABC-treated animal $(n=3)$ were imaged and montaged. The images were thresholded with a predetermined saturation threshold level (MetaMorph) to eliminate background staining. All images were subject to the same saturation threshold. Cells with c-Fos $^{+}$nuclei above threshold were counted in gray matter ipsilateral and contralateral to the graft. The numbers of ipsilateral c-Fos ${ }^{+}$nuclei were statistically compared with the numbers of contralateral c-Fos ${ }^{+}$ nuclei using a Student's $t$ test (Microsoft Excel). Significance was determined if $p<0.05$.

\section{Results}

\section{Chondroitinase $\mathrm{ABC}$ treatment digests CSPGs within a chronic scar}

CSPGs are quickly upregulated within the glial scar, but new production of most forms subsides within 1 month after injury (Jones et al., 2003; Tang et al., 2003). Because we planned on grafting PNs into 2-month-old, chronic, unilateral contusion sites, we needed to determine whether multifocal treatment with ChABC would be sufficient to digest the deposited CSPGs associated with the scar around the time of grafting and active axonal growth into and out of the graft. The expression of intact CSPG (with CS56 antibody) and digested CSPG (with 2B6 antibody) in chronically injured spinal cord $3 \mathrm{~d}$ after being treated with ChABC or PBS was examined. In PBS-treated tissue, there was abundant CS56 immunoreactivity (Fig. 2a) and virtually no 2B6 immunoreactivity (Fig. 2c) in tissue surrounding the lesion. After ChABC treatment, staining with the CS56 antibody was virtually absent (Fig. $2 b$ ) in the lesion penumbra. There was a corresponding increase in 2B6 immunoreactivity in tissue surrounding the lesion site (Fig. $2 d$ ). These data suggest that administration of ChABC sufficiently digests CSPGs associated with a chronic glial scar.
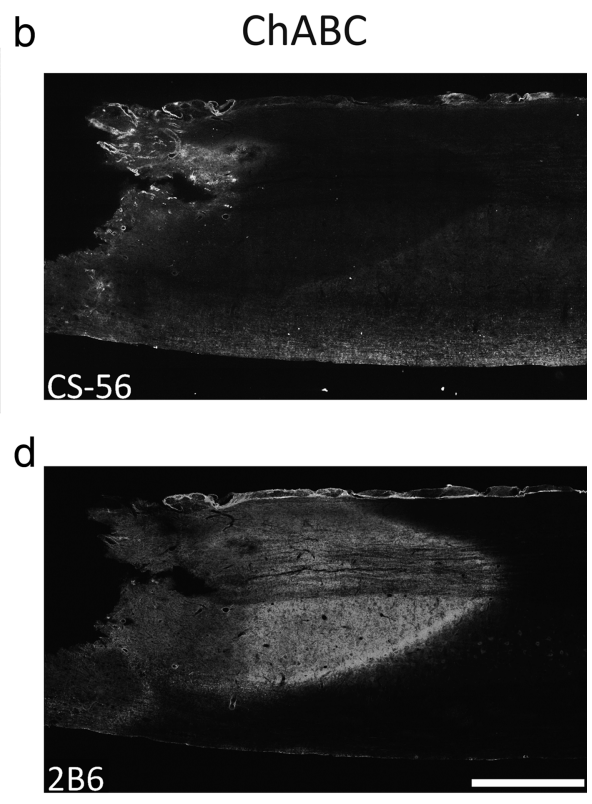

$2 \mathrm{~B} 6$

Figure 2. Chondroitinase $A B C$ treatment of a chronic glial scar digests CSPG. Shown are horizontal sections of chronically injured spinal cord $3 \mathrm{~d}$ after PBS or ChABC treatment. In PBS-treated tissue, there was abundant staining with the CS56 antibody that binds ce of intact CSPG within the lesion penumbra. After ChABC treatment, nearly all CSPG was digested. There was very little Chondroitinase $\mathrm{ABC}$ treatment promotes behavioral recovery after chronic SCI

The unilateral contusion model used in this study produces virtually complete destruction of gray matter and sparing of a thin rim of white matter at the lesion epicenter and results in significant, long-lasting deficits (Sandrow et al., 2008). To determine whether ChABC treatment improves function in chronically injured animals that receive delayed PNGs, forelimb use by GDNFPBS-treated or GDNF-ChABC-treated animals was assessed using several methods.

\section{Forelimb locomotor scale}

The abilities of animals to use their affected, right forelimbs in the open field were assessed using the FLS (Cao et al., 2008; Sandrow et al., 2008). Two days after contusion, animals were only capable of slight (FLS score of 1) or extensive (FLS score of 2) movement of one joint, usually the shoulder. At 7 weeks after the initial injury ( 1 week before grafting of PN), all animals spontaneously recovered and were able to plantar place their right forepaw frequently (FLS score of 10) or continuously (FLS score of 11) (Fig. 3a,b). Despite this recovery process, all animals remained significantly impaired from their baseline abilities $(p=0.0001)$.

After GDNF-PBS or GDNF-ChABC treatment of a 2-monthold contusion site and grafting of a PN to span the cavity, there was an initial decrease in FLS scores, followed by a period of significant recovery $\left(F_{(7,119)}=28.9 ; p=0.0001\right)$. The grafting procedure left animals in both groups capable of extensively moving two joints, typically the shoulder and elbow, and slightly moving the wrist (mean \pm SEM scores: GDNF-PBS, $5.4 \pm 0.63$; GDNF-ChABC, $5.23 \pm 0.55$ ). One week after grafting, both groups recovered to a score of 7 , indicating plantar placement of the forelimb with no weight support. Functional impairments remained similar in both GDNF-PBS-treated and GDNFChABC-treated animals over the 7 week period. At 8 weeks after grafting, the ChABC-treated group had an FLS score of $9.6 \pm 0.43$ 
a

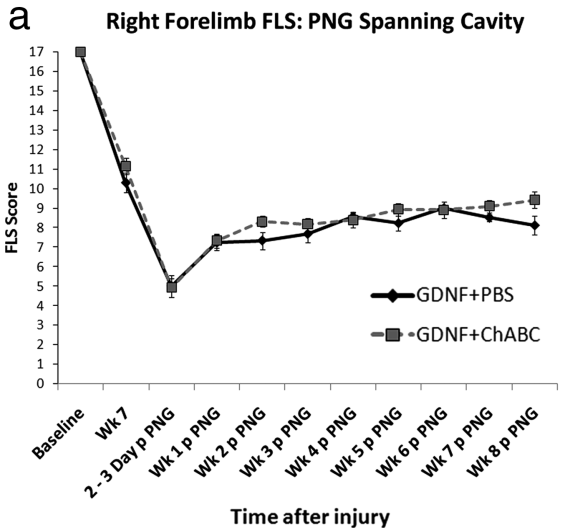

b

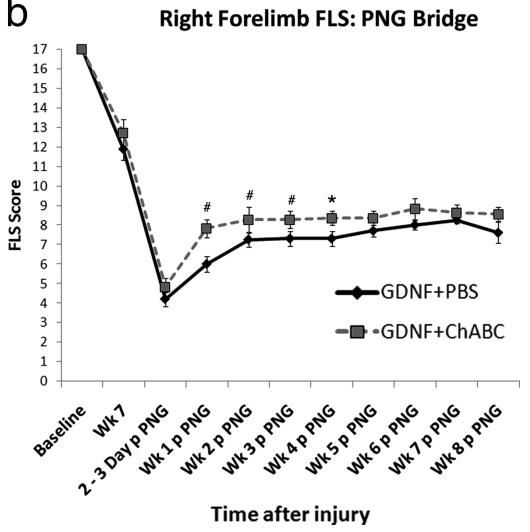

Figure 3. Forelimb locomotor scale scores after combining chondroitinase $A B C$ treatment, GDNF, and peripheral nerve grafting in chronically injured animals. The ability of chronic, 55 hemicontused animals to use their affected forepaws after GDNF-PBS or GDNF-ChABC treatment and grafting of PN was assessed with the FLS. There was no difference in FLS scores between treatment groups (PBS: black line, $n=10$; ChABC: gray line, $n=14$ ) before or after grafting in animals that had PNGs spanning the chronic contusion site $(\boldsymbol{a})$. However, there were significant differences in animals that received treatment before grafting a PN bridge $(\boldsymbol{b})$. Animals that received GDNF-ChABC before grafting one end of a PN into a chronic $C 5$ contusion cavity and ChABC before apposing the other end of the PN into a C7DQ injury site (gray line; $n=13$ ) had higher FLS scores than those treated with GDNF-PBS at C5 and PBS at $C 7$ (black line; $n=11$ ) at earlier time points after graft apposition. ${ }^{\#} p<0.01 ;{ }^{*} p<0.05$. Error bars represent SEM.
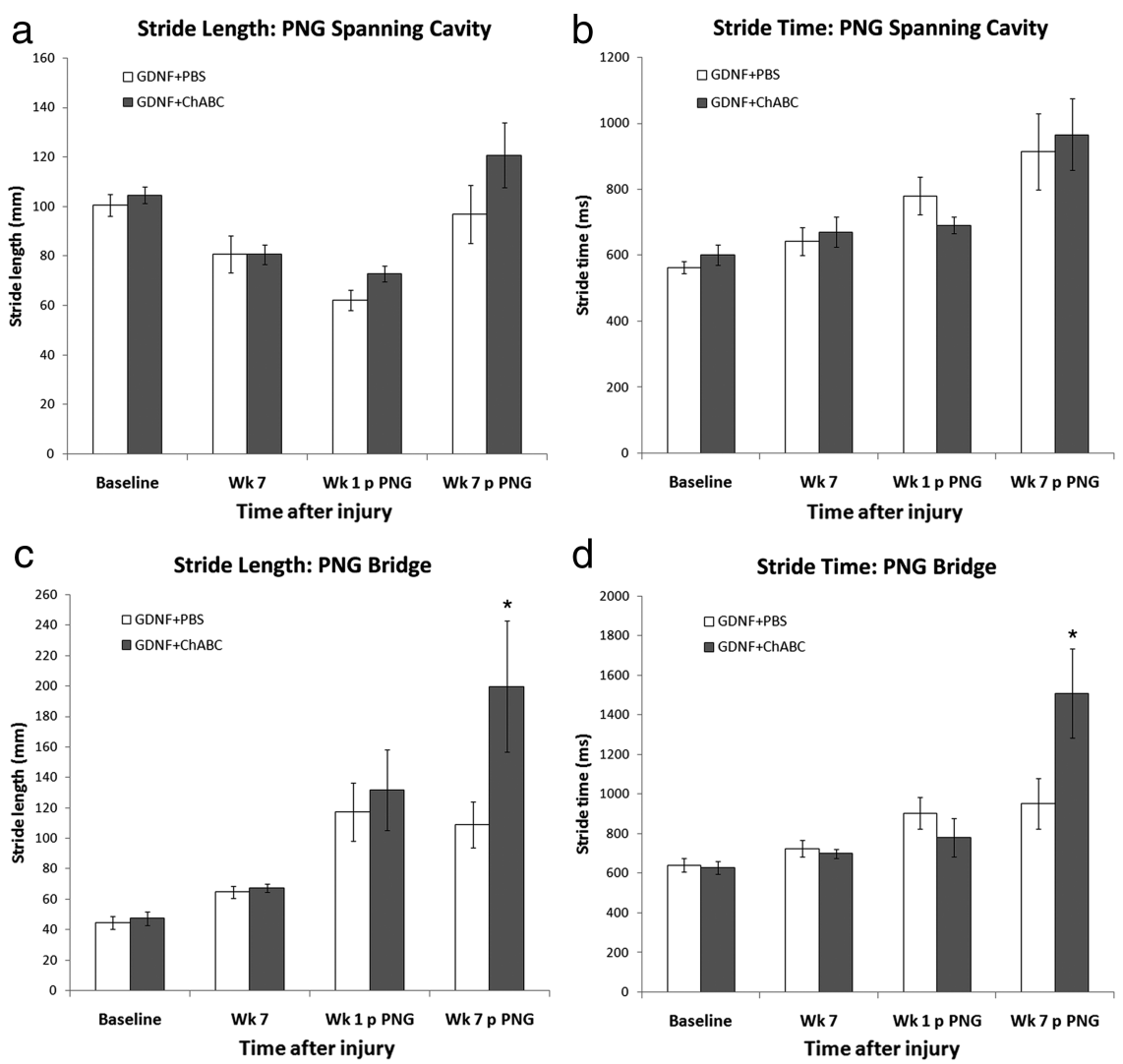

Figure 4. Administration of chondroitinase into a chronic injury setting affects gait characteristics. The Tread Scan system was used to analyze different parameters during locomotion. No difference in stride length $(\boldsymbol{a})$ or stride time $(\boldsymbol{b})$ was determined at before and after PN grafting time points between animals with PNGs spanning a chronic $C 5$ contusion site treated with GDNF-PBS (white bars; $n=10$ ) or GDNF-ChABC (gray bars; $n=14$ ). However, animals that received GDNF-ChABC treatment of a chronic contusion site and $\mathrm{ChABC}$ of a distal DQ injury site $(n=13)$ before PN bridging had significantly longer stride lengths $(c)$ and stride times (d) than GDNF-PBS-treated ones $(n=11)$ by 7 weeks after graft apposition. ${ }^{*} p<0.05$. Error bars represent SEM.

( $p=0.082$ ), which corresponds to dorsal stepping with occasional plantar placement. The PBS-treated group was capable only of completing dorsal placements $(8.7 \pm 0.73)$, but scores were not significantly different.

After grafting of a PN to "bridge" a chronic C5 contusion site treated with GDNF-PBS or GDNF-ChABC at the time of proximal graft apposition and a PBS-treated or ChABC-treated C7DQ site, there were deficits in all animals in the open field that spontaneously recovered over time $\left(F_{(8,120)}=15.6 ; p=0.0001\right)$. The ChABC-treated and PBS-treated groups displayed similar impairments $2 \mathrm{~d}$ after apposition. The PBS group had scores of $4.45 \pm 0.41$, indicating extensive movement of the shoulder and slight movement of the elbow and wrist; the ChABC group had scores of $5.5 \pm 0.49$, signifying extensive movement of the shoulder and elbow with slight movement of the wrist. From 1 to 4 weeks after graft apposition, animals treated with $\mathrm{ChABC}$ had significantly higher FLS scores (week 1: PBS, $6.6 \pm 0.7$ and ChABC, $7.9 \pm 0.4, p=$ 0.008 ; week 2: PBS, $7.8 \pm 0.6$ and ChABC, $8.2 \pm 0.5, p=0.009$; week 3: PBS, $7.8 \pm$ 0.6 and ChABC, $8.2 \pm 0.4, p=0.009$; week 4: PBS, $7.8 \pm 0.6$ and $\mathrm{ChABC}, 8.3 \pm$ $0.3, p=0.014)$ and were able to bear weight on dorsally planted steps (FLS score of $>8$ ). PBS-treated animals were not able to perform similarly to ChABCtreated animals and weight bear with their right forelimb until week 6 . Neither group improved further. Thus, ChABC appeared to accelerate the recovery process when administered in a PNG bridging paradigm.

\section{Quantitative gait assessment with \\ Tread Scan}

We determined whether our treatment strategy resulted in changes in specific gait parameters during forced locomotion on a treadmill that could be quantified using a commercially available, computerized system (Tread Scan).

There were no detectable differences at any time point before or after grafting in stride length (Fig. 4a), stride time (Fig. $4 b$ ), base of support (supplemental Fig. $1 a$, available at www.jneurosci.org as supplemental material), or print area (supplemental Fig. 1c, available at www. jneurosci.org as supplemental material) between GDNF-PBS or GDNF-ChABC animals that had PNGs transplanted to span a C5 contusion site.

In animals with PNGs bridging a chronic C5 contusion site and a C7DQ site, there were no differences in print area (supplemental Fig. 1d, available at www. jneurosci.org as supplemental material) or base of support (supplemental Fig. 1b, available at www. jneurosci.org as supplemental material) at any time point before or after apposition of the PN into the C7DQ between PBS-treated 
a
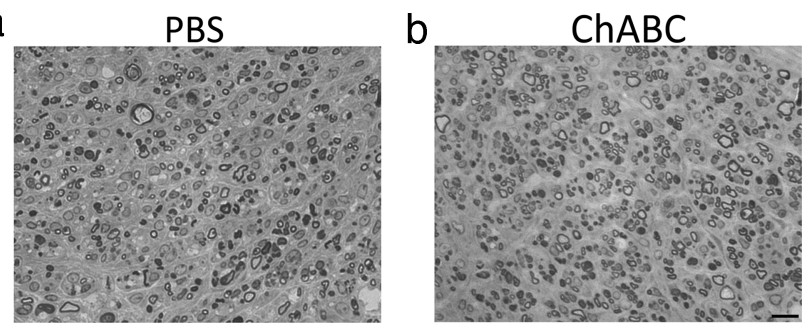

Figure 5. Treatment of a chronic contusion site with chondroitinase $A B C$ does not improve regeneration of axons into a peripheral nerve graft. Segments of a PNG bridge that was transplanted into a chronic $(5$ hemicontusion site that was treated with either GDNF-PBS $(\boldsymbol{a} ; n=5)$ or GDNF-ChABC $(\boldsymbol{b} ; n=5)$ were processed for semithin sectioning to assess the number of myelinated, chronically injured axons that grew into it. Many long-injured axons were capable of regenerating into grafted PNs after either treatment. There was no significant difference in the number of axons between groups. Scale bar, $10 \mu \mathrm{m}$.

and ChABC-treated animals. However, although there were no significant differences in stride length (Fig. $4 c$ ) or stride time (Fig. $4 d$ ) before and soon after grafting, by 7 weeks after graft apposition, ChABC-treated animals had significantly longer stride lengths (Fig. 4c) $(200 \pm 43 \mathrm{~mm} ; p=0.032)$ and stride times (Fig. 4d) $(1508 \pm 225 \mathrm{~ms} ; p=0.034)$ compared with PBS-treated animals (stride length, $109 \pm 15 \mathrm{~mm}$; stride time, $952 \pm 126 \mathrm{~ms}$ ). These findings indicate that ChABC treatment of chronically injured spinal cord with a PNG bridge affects gait patterns such that the animal is able to use its injured forelimb to complete longer steps.

Grid walking and grooming

Animals were also assessed on their abilities to correctly place their right forelimb to walk on a grid platform (Shumsky et al., 2003) (supplemental Fig. 2, available at www.jneurosci.org as supplemental material) and to use their right forelimb to groom themselves (Gensel et al., 2006) (supplemental Fig. 3, available at www.jneurosci.org as supplemental material). There were no significant differences between PBS and ChABC treatment groups with either grafting paradigm.

\section{Chondroitinase $\mathrm{ABC}$ treatment does not affect regrowth of chronically injured axons into a peripheral nerve graft} Because we observed some functional differences between ChABC-treated and PBS-treated groups in both grafting paradigms, we examined whether $\mathrm{ChABC}$ promoted greater regeneration of chronically injured axons that could mediate this recovery. Semithin sections were processed to identify myelinated axons that extended into a PN bridge that was grafted into a 2-month-old, unilateral contusion site that had been treated with PBS or ChABC. After either treatment, there was considerable regrowth into a PNG (Fig. 5). Grafts were well vascularized, and no evidence of necrotic cell content was observed for at least 2 months after transplantation (Fig. $5 a, b$ ). After PBS treatment, there were $2741 \pm 677$ myelinated axons (Fig. 5a) in the graft. After ChABC treatment, $3953 \pm 737$ myelinated axons (Fig. 5b) regenerated into the $\mathrm{PNG}$, but this was not significantly different from the control $(p=0.2)$. This indicates that digestion of CSPGs is not necessary to attract regeneration of chronically injured axons into a PNG.

Chondroitinase $\mathrm{ABC}$ treatment of a chronic contusion site allows regenerating axons to extend beyond a peripheral nerve graft spanning the cavity

Treating a distal graft-host interface with ChABC has been demonstrated to increase axonal regeneration out of the graft and back into host tissue in an acute injury setting (Chau et al., 2004; Fouad et al., 2005; Houle et al., 2006; Tom and Houlé, 2008). We sought to determine whether ChABC also promoted chronically injured, regenerating axons to emerge from a PNG. Axons that had regenerated into the graft were labeled with BDA. There were no $\mathrm{BDA}^{+}$axons in spared tissue immediately medial to the graft, indicating that BDA labeling was specific to axons within the PNG (Fig. 6). Many BDA ${ }^{+}$axons were observed to have grown throughout the grafts following the longitudinal orientation of the grafts, demonstrating good apposition in both groups (Fig. 6). Additionally, virtually all sections examined contained a lesion cavity that housed at least a portion of the PNG, indicating that the PNG nearly filled the cavity (data not shown).

Although many $\mathrm{BDA}^{+}$axons were present in the graft in GDNF-PBS-treated tissue (Fig. $6 a, b)$, very few axons $(5.8 \pm 1.5$ axons per 10 sections) were found $100 \mu \mathrm{m}$ caudal to the distal interface. Rather, many axons at the caudal end had dystrophic end balls (Fig. $6 a^{\prime}$, arrowheads). Other $\mathrm{BDA}^{+}$axons turned around at the distal interface as if they were repelled by the inhibitory environment of the glial scar (Fig. $6 b^{\prime}$, arrow). Both phenotypes are hallmarks of abortive regeneration (Ramon y Cajal, 1928).

After GDNF-ChABC treatment, significantly more axons that grew into the PNG spanning the contusion cavity were able to cross the distal interface $(37.2 \pm 5.7$ axons per 10 sections; $p=0.0001)$. Multiple $\mathrm{BDA}^{+}$profiles were found coursing across the interface into host tissue (Fig. $6 d^{\prime \prime}$, arrowheads). Some $\mathrm{BDA}^{+}$axons that grew into tissue caudal to the graft took a cursive track (Fig. $6 c^{\prime}$, arrow), strongly indicative of frank regeneration (Steward et al., 2003). Other chronically injured, regenerated axons that emerged from the graft were capable of growing several millimeters from the distal boundary (Fig. $6 d^{\prime}$, asterisk). These results are starkly different from that of the control group (GDNF-PBS treatment), suggesting that $\mathrm{ChABC}$ treatment of a chronic injury site allows damaged axons that regenerated into a PNG to reenter host tissue.

Chondroitinase treatment of a caudal injury site results in chronically injured axons regenerating out of a peripheral nerve graft bridge

We had previous success promoting acutely injured axons to regenerate after ChABC in a model in which a PNG bridged a hemisection and a caudal DQ injury (Houle et al., 2006). Here we tested, in a similar model, whether ChABC treatment of a distal, acute C7DQ injury site allowed chronically injured axons to emerge from a graft whose proximal end was placed into a chronic C5 contusion site treated with either GDNF-PBS or GDNF-ChABC to correlate with the functional differences described above. After PBS treatment of the C7 site, few BDA ${ }^{+}$ axons ( $1.4 \pm 0.36$ axons per section) were found in tissue $500 \mu \mathrm{m}$ ventral to the distal graft interface (Fig. 7a); most axons remained in the PNG. Significantly more $\mathrm{BDA}^{+}$axons were found to extend farther into ventral tissue after ChABC treatment $(6.5 \pm 1.0$ axons per section; $p=0.00005$ ) (Fig. $7 b, c$, arrowheads). Axons were found throughout intermediate gray matter and a few axons grew into ventral white matter. These results indicate that ChABC treatment of a distal graft interface allows more chronically injured axons to regenerate out of a PNG bridge.

\section{Electrical stimulation of a peripheral nerve graft bridge induces c-Fos expression in host spinal cord}

An advantage of using a PNG bridge that lies outside of the spinal cord is the ability to specifically identify and stimulate axons that 

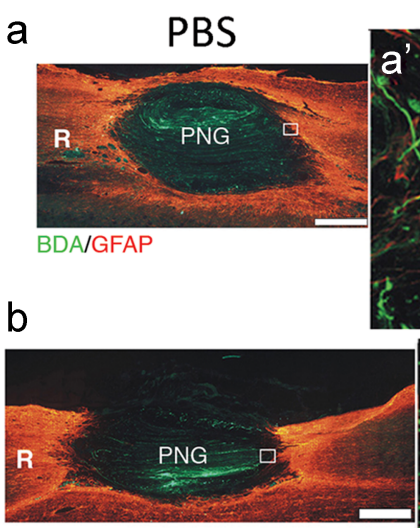

BDA/GFAP
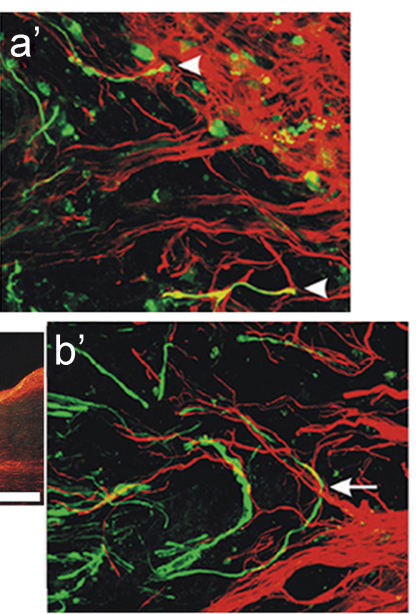
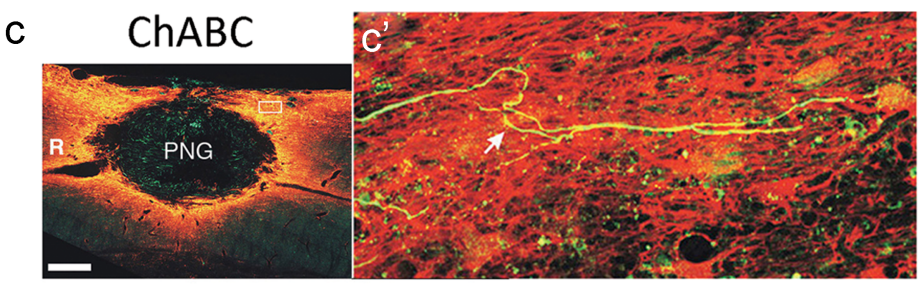

d

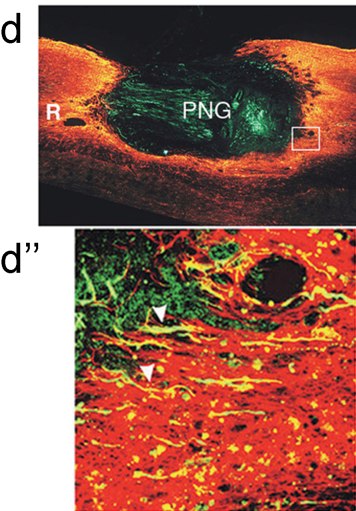

Figure 6. Chondroitinase $A B C$ treatment allows long-injured axons to extend beyond a peripheral nerve graft spanning a cavity. Horizontal sections of hemicontused $C 5$ spinal cord containing a PNG are depicted. Chronically injured axons that grew into the PNG were labeled with BDA (green). GFAP ${ }^{+}$astrocytes (red) demark the boundary of host spinal cord tissue and the graft. In PBS-treated tissue $(n=9), B D A+$ axons were able to grow up to the distal interface but failed to extend beyond it $(\boldsymbol{a}, \boldsymbol{b})$. Rather, they displayed hallmarks of regenerative failure, including bulbous, dystrophic endings ( $\boldsymbol{a}^{\prime}$, arrowheads), and turning at the inhibitory boundary ( $\boldsymbol{b}^{\prime}$, arrow). Conversely, ChABC treatment allowed many chronically injured axons to cross the interface ( $\boldsymbol{d}^{\prime \prime}$, arrowheads; $n=12$ ) into astrocyte-rich territory. Some axons took a cursive course through host tissue ( $\boldsymbol{c}^{\prime}$, arrow), indicating that they regenerated. BDA ${ }^{+}$fibers were found several millimeters away from the distal interface ( $\boldsymbol{d}^{\prime}$, asterisk). Significantly more BDA ${ }^{+}$fibers were found in tissue $100 \mu$ m caudal to the distal interface after ChABC treatment ( $37.2 \pm 5.7$ axons per 10 sections) than PBS treatment (5.8 \pm 1.5 axons per 10 sections; $p=0.0001$ ). Insets $\boldsymbol{a}^{\prime}, \boldsymbol{b}^{\prime}$, and $\boldsymbol{c}^{\prime}$ are higher-magnification images of the boxed regions in $\boldsymbol{a}, \boldsymbol{b}$, and $\boldsymbol{c}$, respectively. $\boldsymbol{d}^{\prime}$ is a high-magnification image of the rightmost boxed region in caudal tissue (C) in $\boldsymbol{d}$. $\boldsymbol{d}^{\prime \prime}$ is a high-magnification image of the boxed region at the interface in $\boldsymbol{d}$. R, Rostral. Scale bar, $500 \mu \mathrm{m}$.

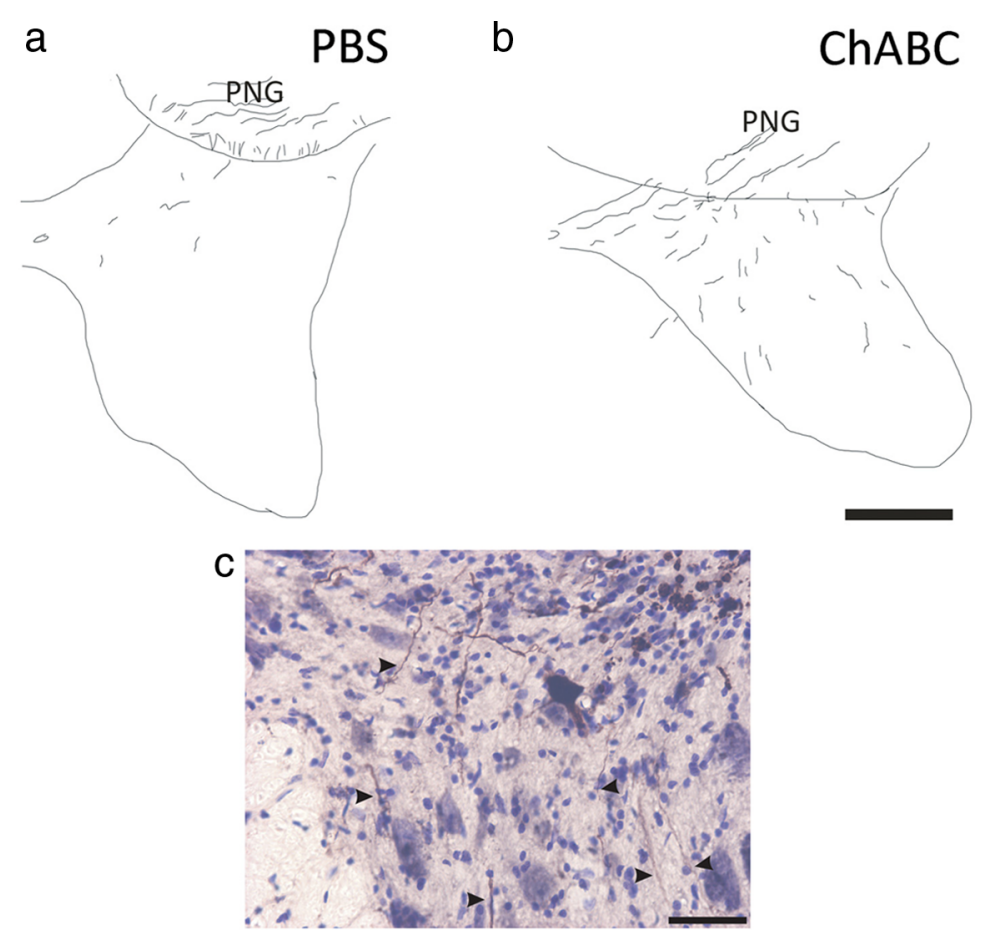

Figure 7. Treatment with chondroitinase $A B C$ promotes chronically injured axons to regenerate out of a peripheral nerve graft bridge. Transverse sections of spinal cord containing a PN apposed to a C7DQ injury were reacted with DAB to visualize BDA-labeled chronically injured axons that grew into the PNG. Tracings of representative montages are represented in $\boldsymbol{a}$ and $\boldsymbol{b}$. Few BDA ${ }^{+}$ axons were seen in tissue $500 \mu \mathrm{m}$ ventral to the graft $(\boldsymbol{a})$ after PBS treatment (1.4 \pm 0.36 axons per section; $n=10)$. However, after administration of $\mathrm{ChABC}(n=6)$, many more labeled axons regenerated out of the graft $(\boldsymbol{b} ; 6.5 \pm 1.0$ axons per section; $p=$ 0.00005 ) and could be found in ventral, ipsilateral tissue. A high-magnification image of BDA ${ }^{+}$axons (highlighted by arrowheads) extending into ventral, ipsilateral gray matter of a representative, ChABC-treated section is shown in c. Scale bars: (in $\boldsymbol{b}$ ) $\boldsymbol{a}, \boldsymbol{b}, 250$ $\mu \mathrm{m} ; \mathrm{c}, 50 \mu \mathrm{m}$. have regenerated into the graft. Thus, it is possible to determine whether the axons that emerged from the PNG to reenter host tissue ventral to the graft interface made functional synapses with host neurons. The PNG bridge of animals whose C7DQ lesion site was acutely treated with vehicle $(n=3)$ or $\operatorname{ChABC}(n=3)$ was stimulated for $1 \mathrm{~h}$, and the animals were killed $2 \mathrm{~h}$ later. There were very few neurons in sections of vehicle-treated animals expressing c-Fos, a marker of transsynaptic neuronal activation (Luckman et al., 1994), mainly near the graft-host interface (less than five neurons per section; data not shown). Conversely, c-Fos was expressed by host neurons in ChABCtreated animals throughout ipsilateral gray matter ventral to the graft $(16.9 \pm 1.4$ neurons per section) (Fig. $\left.8 a, a^{\prime}, b\right)$. c-Fos was found in neurons within ipsilateral ventral horn and ipsilateral intermediate gray. There were significantly fewer neurons contralateral to the graft $(2.8 \pm 0.4$ neurons per section) that were positive for c-Fos expression (Fig. 8 $\left.8 a^{\prime \prime}, b\right) \quad(p=$ 0.0000002 ), and these neurons were confined to the ventral horn.

\section{Discussion}

The challenges of treating chronic SCI are daunting. There is an established glial scar 
rich with inhibitors. Chronically injured neurons may have undergone atrophy or death (Kobayashi et al., 1997; Bregman et al., 1998; Liu et al., 2002; Tobias et al., 2003), and those that survive express low levels of regeneration-associated genes (RAGs) (Tetzlaff et al., 1991; Storer et al., 2003) and have diminished conduction efficiencies (Nashmi and Fehlings, 2001; Tan et al., 2007; Arvanian et al., 2009). Thus, their behavior and physiology is quite different from acutely injured neurons, and it cannot be assumed that a strategy effective in promoting axonal regeneration and functional recovery in an acute injury setting will be successful in a chronic situation. Although ChABC treatment promotes acutely injured axons to regenerate out of grafts (Chau et al., 2004; Fouad et al., 2005; Houle et al., 2006), it was critical that this strategy also be tested after a long-established injury.

Here we showed that ChABC treatment of SCI sites facilitates the emergence of chronically injured, regenerating axons from a PN grafted into a 2-month-old, cervical, unilateral, contusion site and their reentry into host spinal cord tissue. At least some of these regenerated axons mediate some function, evidenced by the differences in gait parameters between ChABC-treated and PBS-treated animals (Fig. 4) and the induction of c-Fos in host neurons ipsilateral to the PNG after electrical stimulation of the PN (Fig. 8). Although we did not distinguish any differences in the final FLS scores of PBS-treated and ChABC-treated animals, early stages of recovery were accelerated in animals receiving $\mathrm{ChABC}$ treatment. Although the observed improvements were incremental, it is noteworthy that there was any improvement at all as the potential for recovery greatly diminishes with increasing time after injury. Previous work indicates that a varied population of injured brainstem and propriospinal neurons regrow axons into a PN grafted after a cervical contusion injury (Sandrow et al., 2008). In this study, it is unclear which particular regenerated tract(s) contributed to the increase in stride length and stride time in ChABC-treated animals.

That we observed c-Fos ${ }^{+}$neurons after electrically stimulating axons within the graft is significant because it provides direct evidence that regenerated, chronically injured axons were capable of reforming functional synapses. It is highly likely that the $\mathrm{c}-\mathrm{Fos}^{+}$neurons were motoneurons and interneurons because of the location and morphology of these cells within the ventral horn and intermediate gray. Although these synapses appeared to be functional, it is unclear how efficient these connections were in transducing information. It is possible that the regenerated axons remained in a pathological state. Tan et al. (2007) demonstrated that injured sensory axons have decreased conduction velocities even after regeneration, which was thought to be primarily attributable to these axons being chronically demyelinated. Although we have evidence that axons regenerating in our grafts are myelinated (Fig. 5), we do not know whether the thickness of the myelin surrounding the axons approaches normal. We also do not know whether these axons possess the proper amounts and patterns of channels necessary for typical signal propagation. Thus, it is conceivable that, although regenerated axons reformed functional synapses on host neurons, the efficiency of these con- nections was limited. This may explain why only limited functional recovery was observed.

Another factor likely contributing to the limited recovery is the loss of motoneurons because of the original injury. Because no strategy was used to replace these neurons, the function that these neurons mediated was permanently lost.

ChABC did not increase the number of axons that regrew into the PNG (Fig. 5), suggesting that the increased expression of neurotrophins (Meyer et al., 1992; Funakoshi et al., 1993) and/or extracellular matrix proteins (Lefcort et al., 1992; Wang et al., 1992) by the Schwann cells in the graft in response to the tibial nerve injury was sufficient to overcome the potently inhibitory nature of the scar.

Although ChABC allowed more long-injured, regenerating axons to emerge from a PN than did PBS treatment, there were fewer axons in tissue beyond the ChABC-treated distal interface than were found previously with acutely injured axons (Tom and Houlé, 2008). This was despite administering GDNF to the chronic lesion cavity and surrounding tissue before grafting the PN. Thus, it seems that using GDNF did not fully maximize the potential of chronically injured axons to regenerate. It will be necessary to determine whether using GDNF in combination with other stimulatory factors, such as other neurotrophins (increased via exogenous or endogenous [e.g., forced exercise (Ying et al., 2005; Sandrow-Feinberg et al., 2009)] means), cAMP (Gao et al., 2004; Lu et al., 2004; Nikulina et al., 2004; Pearse et al., 2004), or immune-associated proteins (Yin et al., 2006) will increase extension of these injured axons. Expressing neurotrophins beyond the distal interface may give additional incentive to more axons to leave the growth-supportive environment of the PN and reenter host tissue (Taylor et al., 2006).

GDNF has been suggested to affect Schwann cell/astrocyte interactions at graft-host interfaces such that there is some attenuation of gliosis and more intermingling of the normally antagonistic cell types (Deng et al., 2008). We did not observe gross migration of GFAP ${ }^{+}$astrocytes into the graft (Fig. 6) after GDNF administration. This is likely because our GDNF treatment was relatively brief $(1 \mathrm{~h})$ and was not sustained for an extended period of time. However, both PBS-treated and ChABC-treated groups received GDNF, suggesting that even if the neurotrophin influenced the interactions between astrocytes and Schwann cells, it 
was not sufficient to promote extensive growth beyond the interface, demonstrated by the paucity of axons in tissue beyond a GDNF-PBS-treated graft site.

Grafting a PN into a highly relevant cervical contusion injury model hopefully will be translatable into a clinical setting. Although improving axonal growth out of any type of graft will most certainly be a goal of any future studies, there are advantages and disadvantages with both of the grafting models used in this study. For the paradigm in which a PNG spans the lesion cavity, our priority was to minimize additional tissue injury and maintain as much tissue spared from the initial contusion injury as possible. A limitation with this technique is that axons are not specifically guided toward a target area. Regenerating axons are as likely to encounter gray matter as white matter once they cross the distal graft-host interface. Although both regions have been shown to be growth permissive (Davies et al., 1999; Pettigrew and Crutcher, 1999), supraspinal axons growing in degenerated white matter likely do not see the same developmental cues that would ordinarily direct them to change course and innervate gray matter. Conversely, using the PN bridge model efficiently directs axons into gray matter in close proximity with host interneurons, which appear to play critical roles in plasticity and recovery of function (Bareyre et al., 2004; Courtine et al., 2008). This may increase the probability that axons regenerating out of the $\mathrm{PN}$ will encounter and synapse with a host neuron. However, the obvious drawback with this particular grafting paradigm is that a second, acute injury needs to be created that may incur additional impairments. Thus, the overall gains must be weighed against the costs. We have had some success and observed changes in behavior using the PN bridge model in both an acute (Houle et al., 2006) and a chronic injury setting, suggesting that the PN bridging paradigm, even with its disadvantages, may be beneficial in the end.

Although the combination of PN grafts, ChABC, and GDNF was effective in promoting regeneration of chronically injured axons after a high-level injury, it is not known whether this strategy would be as effective in encouraging regrowth of chronically injured axons damaged at thoracic or lumbar levels of spinal cord. The growth potential of lesioned axons is greater the closer the injury is to the cell body, likely attributable to the induction of RAGs, such as GAP-43 and cytoskeletal proteins, when axotomy occurs at more proximal levels than at distal levels (Doster et al., 1991; Fernandes et al., 1999). Therefore, it would be expected that axons that were injured at a higher level would have greater regenerative capacity than axons injured farther down the spinal cord. Indeed, axons severed at cervical levels regenerate into PNGs better than those injured at thoracic or lumbar levels (Richardson et al., 1984; Amin et al., 2008). It will be interesting to determine whether treating an acute or chronic thoracic or lumbar injury site with GDNF and ChABC before grafting a PN successfully promotes axonal regeneration into and beyond the transplant.

In conclusion, the ability of ChABC to aid regeneration of acutely injured axons after SCI has been well documented (Busch and Silver, 2007; Crespo et al., 2007). The present study presents the first evidence that ChABC treatment is also able to promote regeneration of chronically injured axons. Success was ensured by addressing multiple obstacles that contribute to regenerative failure: helping to overcome a loss of intrinsic growth capacity with neurotrophins, bridging a lesion gap with a growth-promoting PNG, and mitigating the inhibitory nature of the glial scar with ChABC. These data indicate that a multifaceted approach provides the best opportunity for functional axonal regeneration after chronic SCI.

\section{References}

Amin A, Olivier-Lanvin K, Lemay MA, Houle JD (2008) Axon regeneration in a lower thoracic injury following combined treatments of neurotrophins, chondroitinase, peripheral nerve grafting and exercise. Soc Neurosci Abstr 34:74.9.

Arvanian VL, Schnell L, Lou L, Golshani R, Hunanyan A, Ghosh A, Pearse DD, Robinson JK, Schwab ME, Fawcett JW, Mendell LM (2009) Chronic spinal hemisection in rats induces a progressive decline in transmission in uninjured fibers to motoneurons. Exp Neurol 216:471-480.

Bareyre FM, Kerschensteiner M, Raineteau O, Mettenleiter TC, Weinmann O, Schwab ME (2004) The injured spinal cord spontaneously forms a new intraspinal circuit in adult rats. Nat Neurosci 7:269-277.

Basso DM, Beattie MS, Bresnahan JC (1995) A sensitive and reliable locomotor rating scale for open field testing in rats. J Neurotrauma 12:1-21.

Bradbury EJ, Moon LD, Popat RJ, King VR, Bennett GS, Patel PN, Fawcett JW, McMahon SB (2002) Chondroitinase ABC promotes functional recovery after spinal cord injury. Nature 416:636-640.

Bregman BS, Broude E, McAtee M, Kelley MS (1998) Transplants and neurotrophic factors prevent atrophy of mature CNS neurons after spinal cord injury. Exp Neurol 149:13-27.

Busch SA, Silver J (2007) The role of extracellular matrix in CNS regeneration. Curr Opin Neurobiol 17:120-127.

Caggiano AO, Zimber MP, Ganguly A, Blight AR, Gruskin EA (2005) Chondroitinase ABCI improves locomotion and bladder function following contusion injury of the rat spinal cord. J Neurotrauma 22:226-239.

Cao Y, Shumsky JS, Sabol MA, Kushner RA, Strittmatter S, Hamers FP, Lee DH, Rabacchi SA, Murray M (2008) Nogo-66 receptor antagonist peptide (NEP1-40) administration promotes functional recovery and axonal growth after lateral funiculus injury in the adult rat. Neurorehabil Neural Repair 22:262-278.

Chau CH, Shum DK, Li H, Pei J, Lui YY, Wirthlin L, Chan YS, Xu XM (2004) Chondroitinase ABC enhances axonal regrowth through Schwann cellseeded guidance channels after spinal cord injury. FASEB J 18:194-196.

Courtine G, Song B, Roy RR, Zhong H, Herrmann JE, Ao Y, Qi J, Edgerton VR, Sofroniew MV (2008) Recovery of supraspinal control of stepping via indirect propriospinal relay connections after spinal cord injury. Nat Med 14:69-74.

Crespo D, Asher RA, Lin R, Rhodes KE, Fawcett JW (2007) How does chondroitinase promote functional recovery in the damaged CNS? Exp Neurol 206:159-171.

Davies SJ, Goucher DR, Doller C, Silver J (1999) Robust regeneration of adult sensory axons in degenerating white matter of the adult rat spinal cord. J Neurosci 19:5810-5822.

Deng LX, Hu J, Liu NK, Smith GM, Xu XM (2008) GDNF modifies astrogliotic responses at graft-host interfaces allowing robust axonal regeneration into Schwann cell-seeded guidance channels grafted into hemisected adult rat spinal cords. Soc Neurosci Abstr 34:352.19.

Dolbeare D, Houle JD (2003) Restriction of axonal retraction and promotion of axonal regeneration by chronically injured neurons after intraspinal treatment with glial cell line-derived neurotrophic factor (GDNF). J Neurotrauma 20:1251-1261.

Doster SK, Lozano AM, Aguayo AJ, Willard MB (1991) Expression of the growth-associated protein GAP-43 in adult rat retinal ganglion cells following axon injury. Neuron 6:635-647.

Fawcett JW (2006) Overcoming inhibition in the damaged spinal cord. J Neurotrauma 23:371-383.

Fernandes KJ, Fan DP, Tsui BJ, Cassar SL, Tetzlaff W (1999) Influence of the axotomy to cell body distance in rat rubrospinal and spinal motoneurons: differential regulation of GAP-43, tubulins, and neurofilament-M. J Comp Neurol 414:495-510.

Fouad K, Schnell L, Bunge MB, Schwab ME, Liebscher T, Pearse DD (2005) Combining Schwann cell bridges and olfactory-ensheathing glia grafts with chondroitinase promotes locomotor recovery after complete transection of the spinal cord. J Neurosci 25:1169-1178.

Funakoshi H, Frisén J, Barbany G, Timmusk T, Zachrisson O, Verge VM, Persson H (1993) Differential expression of mRNAs for neurotrophins and their receptors after axotomy of the sciatic nerve. J Cell Biol 123:455-465.

Galtrey CM, Fawcett JW (2007) The role of chondroitin sulfate proteogly- 
cans in regeneration and plasticity in the central nervous system. Brain Res Rev 54:1-18.

Gao Y, Deng K, Hou J, Bryson JB, Barco A, Nikulina E, Spencer T, Mellado W, Kandel ER, Filbin MT (2004) Activated CREB is sufficient to overcome inhibitors in myelin and promote spinal axon regeneration in vivo. Neuron 44:609-621.

Gensel JC, Tovar CA, Hamers FP, Deibert RJ, Beattie MS, Bresnahan JC (2006) Behavioral and histological characterization of unilateral cervical spinal cord contusion injury in rats. J Neurotrauma 23:36-54.

Houle JD, Tom VJ, Mayes D, Wagoner G, Phillips N, Silver J (2006) Combining an autologous peripheral nervous system "bridge" and matrix modification by chondroitinase allows robust, functional regeneration beyond a hemisection lesion of the adult rat spinal cord. J Neurosci 26:7405-7415.

Jones LL, Margolis RU, Tuszynski MH (2003) The chondroitin sulfate proteoglycans neurocan, brevican, phosphacan, and versican are differentially regulated following spinal cord injury. Exp Neurol 182:399-411.

Kalil K, Skene JH (1986) Elevated synthesis of an axonally transported protein correlates with axon outgrowth in normal and injured pyramidal tracts. J Neurosci 6:2563-2570.

Kobayashi NR, Fan DP, Giehl KM, Bedard AM, Wiegand SJ, Tetzlaff W (1997) BDNF and NT-4/5 prevent atrophy of rat rubrospinal neurons after cervical axotomy, stimulate GAP-43 and T $\alpha 1$-tubulin mRNA expression, and promote axonal regeneration. J Neurosci 17:9583-9595.

Lefcort F, Venstrom K, McDonald JA, Reichardt LF (1992) Regulation of expression of fibronectin and its receptor, alpha 5 beta 1, during development and regeneration of peripheral nerve. Development 116:767-782.

Liu Y, Himes BT, Murray M, Tessler A, Fischer I (2002) Grafts of BDNFproducing fibroblasts rescue axotomized rubrospinal neurons and prevent their atrophy. Exp Neurol 178:150-164.

Lu P, Yang H, Jones LL, Filbin MT, Tuszynski MH (2004) Combinatorial therapy with neurotrophins and cAMP promotes axonal regeneration beyond sites of spinal cord injury. J Neurosci 24:6402-6409.

Luckman SM, Dyball RE, Leng G (1994) Induction of c-fos expression in hypothalamic magnocellular neurons requires synaptic activation and not simply increased spike activity. J Neurosci 14:4825-4830.

McKeon RJ, Jurynec MJ, Buck CR (1999) The chondroitin sulfate proteoglycans neurocan and phosphacan are expressed by reactive astrocytes in the chronic CNS glial scar. J Neurosci 19:10778-10788.

Meyer M, Matsuoka I, Wetmore C, Olson L, Thoenen H (1992) Enhanced synthesis of brain-derived neurotrophic factor in the lesioned peripheral nerve: different mechanisms are responsible for the regulation of BDNF and NGF mRNA. J Cell Biol 119:45-54.

Nashmi R, Fehlings MG (2001) Changes in axonal physiology and morphology after chronic compressive injury of the rat thoracic spinal cord. Neuroscience 104:235-251.

Nikulina E, Tidwell JL, Dai HN, Bregman BS, Filbin MT (2004) The phosphodiesterase inhibitor rolipram delivered after a spinal cord lesion promotes axonal regeneration and functional recovery. Proc Natl Acad Sci U S A 101:8786-8790.

Pearse DD, Pereira FC, Marcillo AE, Bates ML, Berrocal YA, Filbin MT, Bunge MB (2004) cAMP and Schwann cells promote axonal growth and functional recovery after spinal cord injury. Nat Med 10:610-616.

Pettigrew DB, Crutcher KA (1999) White matter of the CNS supports or inhibits neurite outgrowth in vitro depending on geometry. J Neurosci 19:8358-8366.

Ramon y Cajal S (1928) Degeneration and regeneration of the nervous system. London: Oxford UP.

Richardson PM, Issa VM, Aguayo AJ (1984) Regeneration of long spinal axons in the rat. J Neurocytol 13:165-182.

Ruff RL, McKerracher L, Selzer ME (2008) Repair and neurorehabilitation strategies for spinal cord injury. Ann N Y Acad Sci 1142:1-20.
Sandrow HR, Shumsky JS, Amin A, Houle JD (2008) Aspiration of a cervical spinal contusion injury in preparation for delayed peripheral nerve grafting does not impair forelimb behavior or axon regeneration. Exp Neurol 210:489-500.

Sandrow-Feinberg HR, Izzi J, Shumsky JS, Zhukareva V, Houle JD (2009) Forced exercise as a rehab strategy after unilateral cervical spinal cord contusion injury. J Neurotrauma 26:721-731.

Shumsky JS, Tobias CA, Tumolo M, Long WD, Giszter SF, Murray M (2003) Delayed transplantation of fibroblasts genetically modified to secrete BDNF and NT-3 into a spinal cord injury site is associated with limited recovery of function. Exp Neurol 184:114-130.

Silver J, Miller JH (2004) Regeneration beyond the glial scar. Nat Rev Neurosci 5:146-156.

Steward O, Zheng B, Tessier-Lavigne M (2003) False resurrections: distinguishing regenerated from spared axons in the injured central nervous system. J Comp Neurol 459:1-8.

Storer PD, Dolbeare D, Houle JD (2003) Treatment of chronically injured spinal cord with neurotrophic factors stimulates betaII-tubulin and GAP-43 expression in rubrospinal tract neurons. J Neurosci Res 74:502-511.

Tan AM, Petruska JC, Mendell LM, Levine JM (2007) Sensory afferents regenerated into dorsal columns after spinal cord injury remain in a chronic pathophysiological state. Exp Neurol 206:257-268.

Tang X, Davies JE, Davies SJ (2003) Changes in distribution, cell associations, and protein expression levels of NG2, neurocan, phosphacan, brevican, versican $\mathrm{V} 2$, and tenascin-C during acute to chronic maturation of spinal cord scar tissue. J Neurosci Res 71:427-444.

Taylor L, Jones L, Tuszynski MH, Blesch A (2006) Neurotrophin-3 gradients established by lentiviral gene delivery promote short-distance axonal bridging beyond cellular grafts in the injured spinal cord. J Neurosci 26:9713-9721.

Tester NJ, Howland DR (2008) Chondroitinase ABC improves basic and skilled locomotion in spinal cord injured cats. Exp Neurol 209:483-496.

Tetzlaff W, Alexander SW, Miller FD, Bisby MA (1991) Response of facial and rubrospinal neurons to axotomy: changes in mRNA expression for cytoskeletal proteins and GAP-43. J Neurosci 11:2528-2544.

Tobias CA, Shumsky JS, Shibata M, Tuszynski MH, Fischer I, Tessler A, Murray M (2003) Delayed grafting of BDNF and NT-3 producing fibroblasts into the injured spinal cord stimulates sprouting, partially rescues axotomized red nucleus neurons from loss and atrophy, and provides limited regeneration. Exp Neurol 184:97-113.

Tom VJ, Houlé JD (2008) Intraspinal microinjection of chondroitinase $\mathrm{ABC}$ following injury promotes axonal regeneration out of a peripheral nerve graft bridge. Exp Neurol 211:315-319.

University of Alabama at Birmingham (2008) Spinal cord: facts and figures at a glance. In: Spinal cord injury information network. Birmingham, AL: University of Alabama. Available at www.spinalcord.uab.edu.

Wang GY, Hirai K, Shimada H (1992) The role of laminin, a component of Schwann cell basal lamina, in rat sciatic nerve regeneration within antiserum-treated nerve grafts. Brain Res 570:116-125.

Ye JH, Houle JD (1997) Treatment of the chronically injured spinal cord with neurotrophic factors can promote axonal regeneration from supraspinal neurons. Exp Neurol 143:70-81.

Yin Y, Henzl MT, Lorber B, Nakazawa T, Thomas TT, Jiang F, Langer R, Benowitz LI (2006) Oncomodulin is a macrophage-derived signal for axon regeneration in retinal ganglion cells. Nat Neurosci 9:843-852.

Ying Z, Roy RR, Edgerton VR, Gómez-Pinilla F (2005) Exercise restores levels of neurotrophins and synaptic plasticity following spinal cord injury. Exp Neurol 193:411-419.

Yiu G, He Z (2006) Glial inhibition of CNS axon regeneration. Nat Rev Neurosci 7:617-627. 